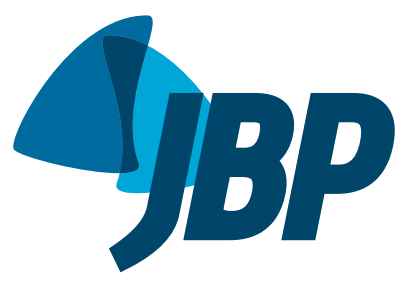

\title{
Pre-treatment with dexamethasone attenuates experimental ventilator-induced lung injury
}

\author{
Fernando Fonseca dos Reis',2, Maycon de Moura Reboredo ${ }^{1,2}$, \\ Leda Marília Fonseca Lucinda ${ }^{1,2}$, Aydra Mendes Almeida Bianchi ${ }^{1,2}$, \\ Maria Aparecida Esteves Rabelo', Lídia Maria Carneiro da Fonseca, ${ }^{1,2}$, \\ Júlio César Abreu de Oliveira1, Bruno Valle Pinheiro ${ }^{1,2}$
}

1. Laboratório de Pesquisa em Pneumologia, Universidade Federal de Juiz de Fora, Juiz de Fora (MG) Brasil.

2. Centro de Biologia da Reprodução, Universidade Federal de Juiz de Fora, Juiz de Fora (MG) Brasil.

Submitted: 17 January 2016 Accepted: 9 May 2016

Study carried out at the Universidade Federal de Juiz de Fora, Juiz de Fora (MG) Brasil.

\begin{abstract}
Objective: To evaluate the effects that administering dexamethasone before the induction of ventilator-induced lung injury (VILI) has on the temporal evolution of that injury. Methods: Wistar rats were allocated to one of three groups: pre-VILI administration of dexamethasone (dexamethasone group); pre-VILI administration of saline (control group); or ventilation only (sham group). The VILI was induced by ventilation at a high tidal volume. Animals in the dexamethasone and control groups were euthanized at 0 , 4,24 , and $168 \mathrm{~h}$ after VILI induction. We analyzed arterial blood gases, lung edema, cell counts (total and differential) in the BAL fluid, and lung histology. Results: At 0, 4, and 24 $h$ after VILI induction, acute lung injury (ALI) scores were higher in the control group than in the sham group $(p<0.05)$. Administration of dexamethasone prior to VILI induction decreased the severity of the lung injury. At $4 \mathrm{~h}$ and $24 \mathrm{~h}$ after induction, the ALI score in the dexamethasone group was not significantly different from that observed for the sham group and was lower than that observed for the control group $(p<0.05)$. Neutrophil counts in BAL fluid were increased in the control and dexamethasone groups, peaking at $4 \mathrm{~h}$ after VILI induction $(p<0.05)$. However, the neutrophil counts were lower in the dexamethasone group than in the control group at $4 \mathrm{~h}$ and $24 \mathrm{~h}$ after induction $(\mathrm{p}<0.05)$. Pre-treatment with dexamethasone also prevented the post-induction oxygenation impairment seen in the control group. Conclusions: Administration of dexamethasone prior to VILI induction attenuates the effects of the injury in Wistar rats. The molecular mechanisms of such injury and the possible clinical role of corticosteroids in VILI have yet to be elucidated.
\end{abstract}

Keywords: Ventilator-induced lung injury; Dexamethasone; Respiratory distress syndrome, adult.

\section{INTRODUCTION}

Although necessary in various types of respiratory failure, mechanical ventilation (MV) can be harmful, especially if its parameters are adjusted incorrectly, because that can result in so-called ventilator-induced lung injury (VILI). (1) VILI can also worsen established lung injury, such as the acute respiratory distress syndrome (ARDS), and delay its healing. (2) The clinical relevance of VILI has been determined by studies conducted in patients with ARDS, in which adjusting protective parameters during MV, mainly limiting the tidal volume and plateau pressure, has been found to decrease mortality. ${ }^{(3,4)}$ In addition, studies involving patients at risk of developing ARDS have shown that those same measures decrease the occurrence of the syndrome and are currently recommended in such patients. ${ }^{(5,6)}$

VILI occurs when the transpulmonary pressure (i.e., the difference between the pressure level in the alveolus and that in the pleural space) is above safe levels and generates high tidal volumes. The pulmonary structures exposed to this high pressure react by generating forces with the same intensity, creating a situation known as lung stress. A high tidal volume induces deformation of the alveolus, which is described as a change in a linear dimension over its initial value, creating a situation known as lung strain. ${ }^{(7,8)}$ VILI can occur even with stress and strain levels lower than those necessary for disruption of alveolar structures, although sufficient to release proinflammatory cytokines and recruit neutrophils, leading to inflammatory lung injury. ${ }^{(9)}$ This biological reaction to mechanical injury is designated biotrauma, and studies have been carried out to establish the mechanisms involved and to test strategies (ventilatory and pharmacological) that could avert or attenuate VILI. ${ }^{(10,11)}$

Glucocorticoids exert anti-inflammatory effects by binding to their receptors in the cytoplasm, forming

\section{Correspondence to:}

Fernando Fonseca dos Reis. Laboratório de Pesquisa Pulmonar, Universidade Federal de Juiz de Fora, Avenida Eugênio do Nascimento, s/n, Dom Bosco, CEP $36038-330$, Juiz de Fora, MG, Brasil

Tel.: 5532 99977-6584. E-mail: fernandocajuri@yahoo.com.br

Financial support: This study was supported by research grants from the Rede Mineira de Ensaios Toxicológicos e Farmacológicos de Produtos Terapêuticos (Rede

Mineira TOXIFAR, Minas Gerais [State] Network of Toxicological and Pharmacological Trials of Therapeutic Products), the Fundação de Amparo à Pesquisa do Estado de Minas Gerais (FAPEMIG, Foundation for the Support of Research in the State of Minas Gerais), and the Centro de Biologia da Reprodução da Universidade Federal de Juiz de Fora (Reproductive Biology Center of the Federal University of Juiz de Fora). 
glucocorticoid-receptor complexes that migrate to the cellular nucleus, where they inhibit the transcription rates of many inflammatory elements, including nuclear factor-kappa B. ${ }^{(12)}$ This decreases the production of proinflammatory cytokines, such as TNF- $a$, IL-1a, IL-1 $\beta$, IL-2, IL-3, IL-5, IL-6, IL-8, IL-12, IFN- $\gamma$, and GM-CSF.(13) By modulating those cytokines, glucocorticoids can suppress granulocyte recruitment and activation, as well as preserving alveolar-capillary barrier integrity and controlling vascular permeability. Glucocorticoids can also inhibit fibroblast proliferation and collagen deposition, both of which are important features in the later phases of ARDS. ${ }^{(14,15)}$

Despite the potentially beneficial effects of glucocorticoids against the mechanisms involved in ARDS and VILI, their clinical usefulness in these conditions is still under debate. ${ }^{(16-20)}$ For instance, in the specific context of the effects of glucocorticoids on mortality, some meta-analyses have shown that they reduce mortality ${ }^{(17,19)}$ whereas other have failed to show a convincing effect of glucocorticoid treatment in ARDS. ${ }^{(20)}$ Hypotheses to explain these dissonant results include lack of an optimal corticosteroid dose, as well as the timing and duration of the therapy. ${ }^{(21)}$

Studies employing experimental models of VILI have obtained promising results with glucocorticoids. However, such studies have evaluated the effect of dexamethasone only in the acute phase of VILI. (22-25) Therefore, the aim of this study was to evaluate the effects that administering dexamethasone before the induction of VILI has on the temporal evolution of the injury. We hypothesized that pre-treatment with dexamethasone would not only attenuate VILI in the acute phase but also accelerate the healing process thereafter.

\section{METHODS}

\section{Animal preparation}

This study was approved by the Animal Research Ethics Committee of the Federal University of Juiz de Fora, in the state of Minas Gerais, Brazil. The animals were cared for in accordance with the guidelines established by the Brazilian National Council for the Monitoring of Animal Experimentation. Sixty-three adult male Wistar rats (mean weight, $286 \pm 15 \mathrm{~g}$ ) were obtained from the animal facility of the Reproductive Biology Center of the Federal University of Juiz de Fora. Over the week prior to the experiment, groups of three animals each were housed in clear plastic cages, with stainless steel wire lids and pinewood shavings as bedding, in a temperature-controlled environment on closed, ventilated shelves, on a 12/12-h light/dark cycle. The animals were fed standard rat chow (mean, $25 \mathrm{~g} /$ day) and had ad libitum access to drinking water.

\section{Experimental protocol}

Animals were allocated to one of three groups (Figure 1): dexamethasone, comprising rats that received an intraperitoneal injection of dexamethasone $(6 \mathrm{mg} / \mathrm{kg}$ ) at 30 min before the induction of VILI $(24,25)$; control, comprising rats that received an intraperitoneal injection of the same volume of saline, also at $30 \mathrm{~min}$ before the induction of VILI; and sham, comprising rats that received neither dexamethasone nor saline, were submitted to normal (non-injurious) ventilation for $10 \mathrm{~min}$, and underwent the same experimental procedures performed in the first two groups.

The rats were anesthetized with intraperitoneal injections of xylazine $(8 \mathrm{mg} / \mathrm{kg})$ and ketamine $(80$ $\mathrm{mg} / \mathrm{kg}$ ). After confirmation of the depth of anesthesia by paw clamp, the animals were intubated with a 16-gauge intravenous catheter and ventilated in the volume-controlled mode with a small animal ventilator (Inspira ASV; Harvard Apparatus, Holliston, MA, USA). To induce VILI (in the dexamethasone and control group rats), the ventilator parameters were set as follows: tidal volume of $35 \mathrm{~mL} / \mathrm{kg}$; respiratory rate of 18 breaths/min; inspiratory to expiratory ratio of $1: 2 ; \mathrm{FiO}_{2}$ of 1 ; and positive end-expiratory pressure (PEEP) of $0 \mathrm{cmH}_{2} \mathrm{O}$. After $1 \mathrm{~h}$ of this injurious MV, the animals were extubated and kept under observation to recover from the anesthesia.

After VILI induction, animals in the dexamethasone and control groups were euthanized $(n=23$ in each group): immediately after VILI induction $(0 h, n=6$ in each group); at $4 \mathrm{~h}$ after VILI induction ( $\mathrm{n}=6$ in each group); at $24 \mathrm{~h}$ after VILI induction ( $\mathrm{n}=6$ in each group); and at $168 \mathrm{~h}$ ( 7 days) after VILI induction ( $\mathrm{n}=5$ in each group). At each of those time points, the animals were again anesthetized with intraperitoneal injections of xylazine $(8 \mathrm{mg} / \mathrm{kg})$ and ketamine $(80 \mathrm{mg} / \mathrm{kg})$, after which a surgical tracheostomy was performed and a 14-gauge cannula was inserted. An arterial catheter was inserted into the left carotid to obtain blood samples for arterial blood gas analysis (ABL90 FLEX; Radiometer, Copenhagen, Denmark). The rats were then paralyzed with an intra-arterial injection of rocuronium $(1 \mathrm{mg} / \mathrm{kg})$ and mechanically ventilated at the following settings: tidal volume of $6 \mathrm{~mL} / \mathrm{kg}$; respiratory rate of 80 breaths/ min; inspiratory to expiratory ratio of $1: 2 ; \mathrm{FiO}_{2}$ of 1 ; and PEEP of $2 \mathrm{cmH}_{2} \mathrm{O}$. After 10 min of ventilation, an arterial blood gas analysis was performed. Subsequently, a laparotomy was performed; the animals were euthanized by exsanguination and sectioning of the diaphragm. The trachea was clamped at end-expiration, with a PEEP of $2 \mathrm{cmH}_{2} \mathrm{O}$, and the lungs were extracted for further analysis. The animals in the sham group $(n=6)$ were euthanized $10 \mathrm{~min}$ after non-injurious MV.

\section{Measurements}

Blood samples for arterial blood gas analysis were obtained after 10 min of protective ventilation, immediately before euthanasia. The lungs were removed en bloc, after which the right lower lobes were separated, fixed in $10 \%$ buffered formaldehyde, and processed for paraffin embedding. Slices ( $4 \mu \mathrm{m}$ in thickness) were cut and stained with hematoxylin-eosin. Morphological examinations were performed by an investigator who 


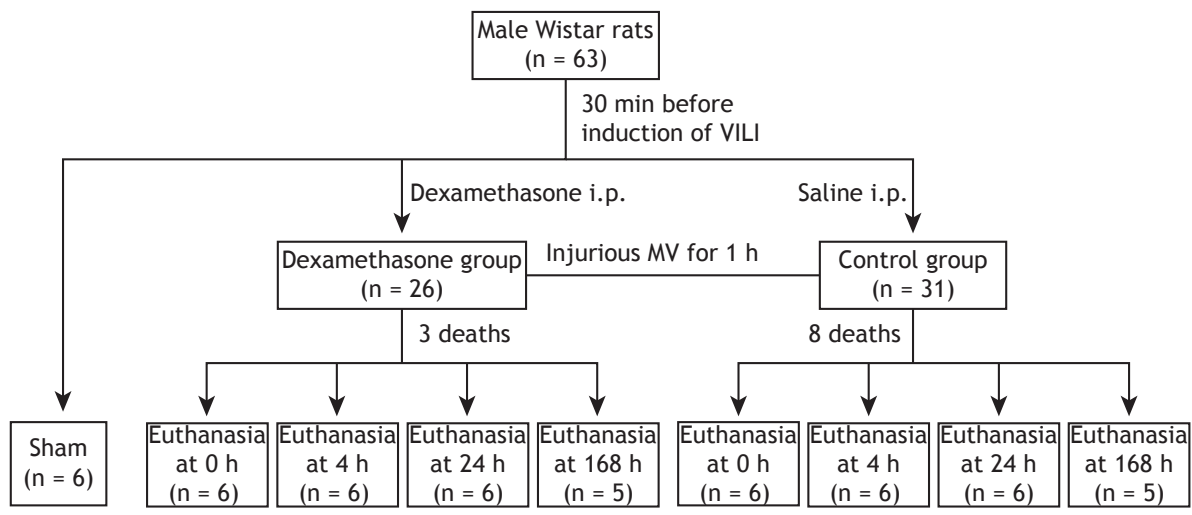

Figure 1. Schematic flow chart of the study design. VILI: ventilator-induced lung injury; and MV: mechanical ventilation.

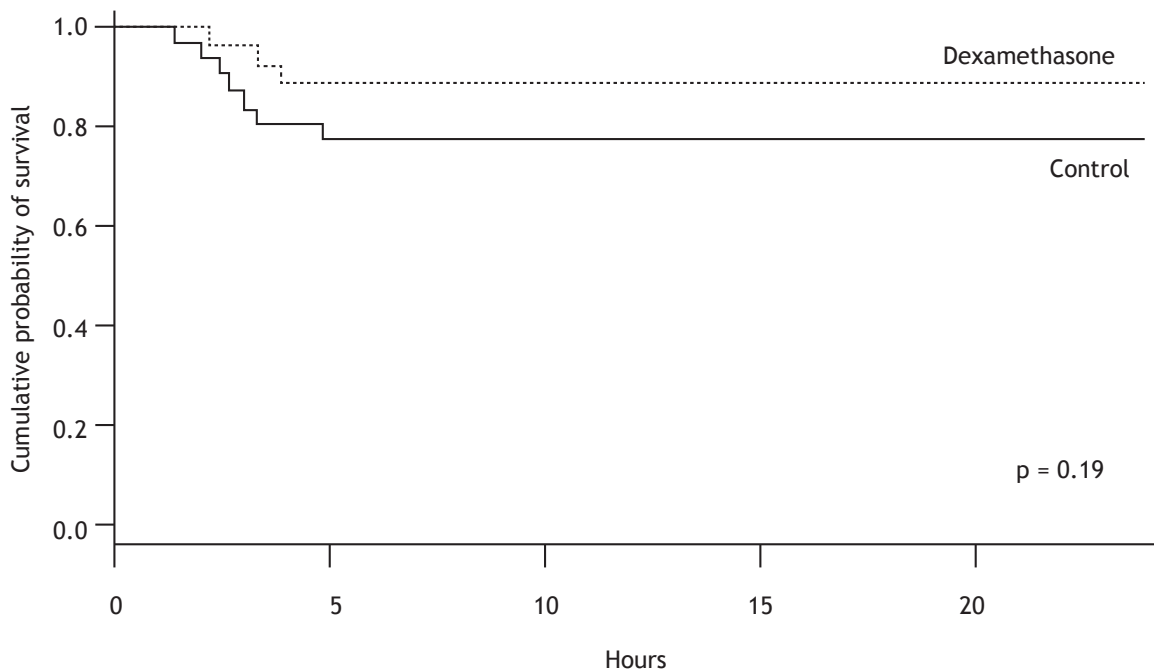

Figure 2. Log-rank test comparison of survival probability within the first $24 \mathrm{~h}$ after induction of ventilator-induced lung injury.

was blinded to the groups, using a conventional light microscope (Carl Zeiss, Hallbergmoos, Germany).

The acute lung injury score, which was the primary outcome measure, was determined by using a weighted scoring system, as described elsewhere. ${ }^{(26)}$ In brief, 20 random fields at a magnification of $\times 400$ were scored independently. Values of 0,1 , or 2 were used in order to represent the severity based on the following findings: neutrophils in the alveolar space, neutrophils in the interstitial space, hyaline membranes, proteinaceous debris filling the airspaces, and alveolar septal thickening. To generate an acute lung injury score, the sum of the five variables was weighted according to the relevance ascribed to each one. The resulting score was a continuous value between 0 (normal) and 1 (the most severe injury). In addition, the extent of each acute lung injury score component was calculated on the basis of the sum of the severity values $(0,1$, or 2$)$ for the 20 fields analyzed.

To obtain a BAL fluid sample, the left lung was washed three times via a tracheal tube with $4 \mathrm{~mL}$ of PBS containing $10 \mathrm{nM}$ of EDTA. Each sample was centrifuged for $10 \mathrm{~min}$ at $1,500 \mathrm{rpm}$ to separate it into its cellular and non-cellular components. The samples were diluted in Türk solution ( $2 \%$ acetic acid), and total leukocyte counts were determined in a Neubauer chamber under light microscopy. The cell pellet was resuspended in PBS and stained with May-Grünwald-Giemsa for differential cell counts, which were performed with a minimum of 300 cells.

The lung wet-to-dry weight ratio was determined in the right upper lobe, as previously described. (27) In brief, the right upper lobe was isolated and weighed (wet weight) using a precise balance (Ohaus Adventurer; Toledo do Brasil, São Bernardo do Campo, Brazil). It was then dried in a microwave at low power (200 W) for $5 \mathrm{~min}$. The drying process was repeated until the difference between two consecutive measurements was less than $0.002 \mathrm{~g}$. The last weight determined was considered the dry weight.

\section{Statistical analysis}

The distribution of the data was tested for normality using the Kolmogorov-Smirnov test. Values are 
expressed as mean \pm standard deviation or median (interquartile range), as appropriate. Data for each group were analyzed by one-way ANOVA followed by the Dunnett's test or by the Kruskal-Wallis test followed by the Mann-Whitney test, as appropriate. Adjustments for repeated measures were performed with Bonferroni correction. Comparisons between the dexamethasone and control groups at each time point were made by unpaired t-test or the Mann-Whitney test, as appropriate. The log-rank test was used for comparison of survival between the dexamethasone and control groups. Values of $p<0.05$ were considered significant. All statistical analyses were performed with the Statistical Package for the Social Sciences, version 17.0 (SPSS Inc., Chicago, IL, USA).

\section{RESULTS}

\section{Survival}

Survival was not initially an objective of this study, and the animals were therefore not followed for a pre-determined period of time specifically for the study of that outcome. However, some deaths were observed in the dexamethasone and control groups during the period between the post-induction anesthesia recovery and the time of euthanasia. Death occurred in $3(12 \%)$ of the 26 animals in the dexamethasone group and in $8(26 \%)$ of the 31 animals in the control group ( $p=$ $0.19)$. Of those 11 deaths, 10 occurred within the first $6 \mathrm{~h}$ after VILI induction, and 1 occurred more than 6 $\mathrm{h}$ but less than $24 \mathrm{~h}$ after VILI induction (Figure 2).

\section{Lung histology and BAL}

At 0,4 , and $24 \mathrm{~h}$ after VILI induction, the rats in the control group showed greater lung injury, as determined by the acute lung injury score, than did those in the sham group. By $168 \mathrm{~h}$ after VILI induction, the mean control group score had decreased and was no different from that observed for the sham group. There were no significant differences between the dexamethasone group and the sham group, in terms of the acute lung injury score, at any of the time points evaluated. There was significantly less lung injury in the dexamethasone group than in the control group at $4 \mathrm{~h}$ and $24 \mathrm{~h}$ after VILI induction (Figure 3).

In the analysis of each component of the acute lung injury score, the animals in the control group showed higher numbers of interstitial neutrophils than did those in the sham group, at 0, 4, and $24 \mathrm{~h}$ after VILI induction, those numbers being highest at $4 \mathrm{~h}$ after VILI induction. No such neutrophil infiltration was seen in the dexamethasone group animals, which showed lower numbers of interstitial neutrophils, compared with the control group, at 4 and $24 \mathrm{~h}$ after VILI induction. Also at $4 \mathrm{~h}$ and $24 \mathrm{~h}$ after VILI induction, there was alveolar neutrophil infiltration in the control group, although not in the sham group. Such infiltration was inhibited by dexamethasone, the animals in the dexamethasone group showing lower numbers of alveolar neutrophils at $4 \mathrm{~h}$ and $24 \mathrm{~h}$ after VILI induction than did the animals in the control group. In addition, proteinaceous debris was more often observed in the control group rats than in the sham group rats at $0 \mathrm{~h}$ and $24 \mathrm{~h}$ after VILI induction (Table 1 ).

In the control group, the BAL neutrophil counts increased after VILI induction, peaking at $4 \mathrm{~h}$ after but returning to levels that were not statistically different from those observed for the sham group at $24 \mathrm{~h}$ and $168 \mathrm{~h}$ after. The BAL neutrophil counts also increased after VILI induction in the dexamethasone group, although to a lesser degree, and were lower in the dexamethasone group than in the control group

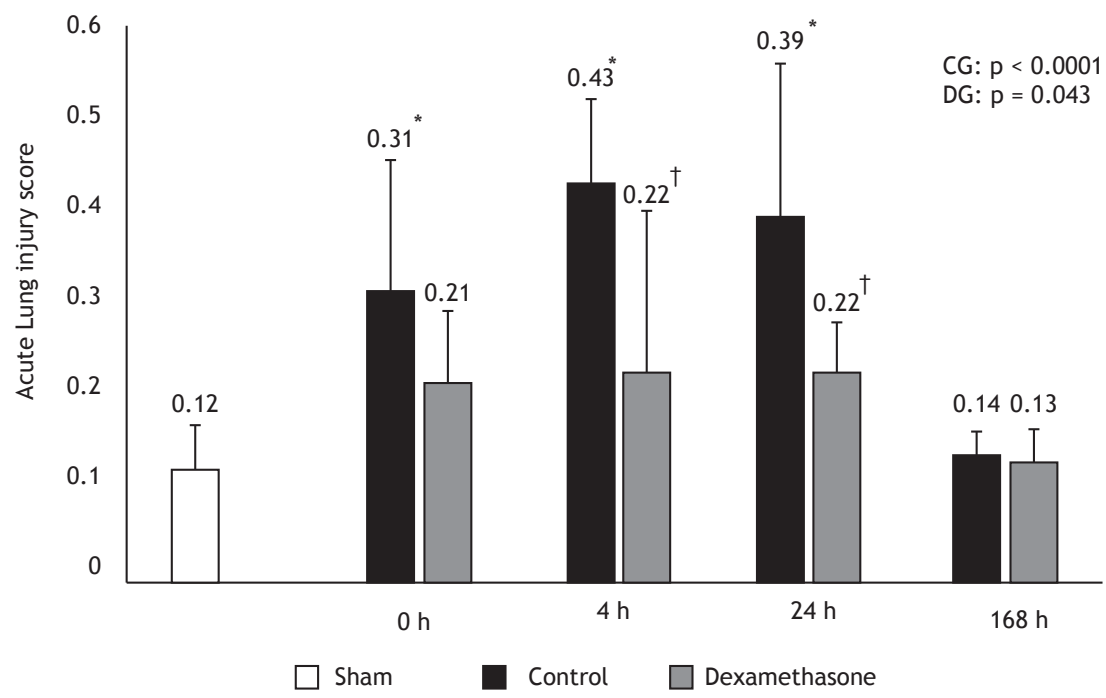

Figure 3. Acute lung injury scores, by group, as well as by time point after the induction of ventilator-induced lung injury in the dexamethasone group (DG) and control group (CG). Data are expressed as mean \pm SD. The $p$-values indicate the overall significance of the differences among the time points and within each group (one-way ANOVA). $* p$ $<0.05$ vs. sham group. ${ }^{\dagger} p<0.05$ vs. control at the same time point. 
at $4 \mathrm{~h}$ and $24 \mathrm{~h}$ after VILI induction. Compared with the control group rats, the dexamethasone group rats showed lower numbers of leukocytes in the BAL at 4 $\mathrm{h}$ after VILI induction (Figure 4).

\section{Arterial blood gases}

Immediately after VILI induction (at $0 \mathrm{~h}$ ), the $\mathrm{PaO}_{2}$ in the control group was lower than that observed for the sham group, although it showed progressive improvement at each subsequent time point. No such impairment in oxygenation was observed in the dexamethasone group (Table 2).

\section{Lung wet-to-dry weight ratio}

No differences in the lung wet-to-dry weight ratio were found between the dexamethasone and control groups.

\section{DISCUSSION}

The main finding of this study was that dexamethasone was able to reduce the inflammatory response caused by VILI and consequently reduce the acute lung injury, as well as attenuating the effects that such injury has on oxygenation. We also demonstrated that VILI occurred early after injurious MV and progressively improved after the removal of the insult, an improvement that was maintained throughout the observation period.

In this model of VILI induction, MV with high tidal volumes resulted in immediate lung injury, characterized by elevated acute lung injury scores after $1 \mathrm{~h}$ of such injurious ventilation. The score remained elevated at $4 \mathrm{~h}$ and $24 \mathrm{~h}$ after the ventilation and eventually normalized by $168 \mathrm{~h}$ after. These findings are in accordance with those of previous studies showing that MV with high tidal volumes can induce VILI within the first 60-90 $\mathrm{min}$. In those studies, the histological alterations peaked within the first $48 \mathrm{~h}$ after the insult and normalized within 7 to 14 days. ${ }^{(23,28)}$

We studied not only the temporal evolution of VILI but also the impact that the administration of an anti-inflammatory drug has on such injury. The decision to administer dexamethasone $30 \mathrm{~min}$ before injurious MV was based on previous experimental studies in which its anti-inflammatory effects on VILI were demonstrated. ${ }^{(24,25)}$ In the present study, the animals that received dexamethasone presented acute lung injury scores comparable to those of the animals in the sham group at all of the time points analyzed. In addition, the acute lung injury scores were lower in the dexamethasone group than in the control group at $4 \mathrm{~h}$ and $24 \mathrm{~h}$ after the injurious MV. That milder lung injury was associated with better oxygenation at the end of the MV. Although neither the inflammatory pathways involved in VILI nor the impact of corticosteroid administration were evaluated, the milder lung injury and the lower pulmonary dysfunction observed among the animals treated with dexamethasone are in accordance with what is already known about the pathophysiology of VILI. It has been shown that MV with high tidal volumes promotes neutrophil chemotaxis and activation in the lungs, by at least two different mechanisms: activation of the transcription factor nuclear factor-kappa $B$, which mediates the release of certain pro-inflammatory cytokines, such as TNF-a, IL-6, and IL-8 ${ }^{(23)}$; and upregulation of CD11b/CD18 induced by the deformation of neutrophils as they pass through pulmonary capillaries compressed by alveoli

Table 1. Acute lung injury scores, by component, in rats submitted to $10 \mathrm{~min}$ of protective mechanical ventilation (sham group) or $1 \mathrm{~h}$ of injurious mechanical ventilation (dexamethasone and control groups, evaluated over time). ${ }^{\mathrm{a}}$

\begin{tabular}{|c|c|c|c|c|c|}
\hline \multirow{2}{*}{$\begin{array}{l}\text { Component } \\
\text { Group }\end{array}$} & \multicolumn{4}{|c|}{ Time point } & \multirow[t]{2}{*}{$p^{b}$} \\
\hline & $\mathbf{O ~ h}$ & $4 \mathrm{~h}$ & $24 \mathrm{~h}$ & $168 \mathrm{~h}$ & \\
\hline \multicolumn{6}{|l|}{ Interstitial neutrophils } \\
\hline Control & $22.8 \pm 6.9^{*}$ & $35.0 \pm 5.2^{*}$ & $30.3 \pm 9.0^{*}$ & $18.0 \pm 3.3$ & $<0.0001$ \\
\hline Dexamethasone & $15.8 \pm 6.6$ & $15.8 \pm 8.4^{\dagger}$ & $18.2 \pm 7.2^{\dagger}$ & $16.8 \pm 4.3$ & NS \\
\hline Sham & $12.3 \pm 4.3$ & 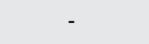 & - & - & \\
\hline \multicolumn{6}{|l|}{ Alveolar neutrophils } \\
\hline Control & $5.5(9.5)$ & $11.5(4.8)^{*}$ & $11(14.3)^{*}$ & $1(0.5)$ & 0.001 \\
\hline Dexamethasone & $4(7.5)$ & $2(6.5)^{\dagger}$ & $3(4)^{\dagger}$ & $1(1)$ & NS \\
\hline Sham & $0.5(2.5)$ & - & - & - & \\
\hline \multicolumn{6}{|l|}{ Hyaline membranes } \\
\hline Control & $0(1)$ & $0(0.3)$ & $0(1.3)$ & $0(0)$ & NS \\
\hline Dexamethasone & $0(1.3)$ & $0(0.5)$ & $0(0.8)$ & $0(0)$ & NS \\
\hline Sham & $0(0)$ & - & - & - & \\
\hline \multicolumn{6}{|l|}{ Proteinaceous debris } \\
\hline Control & $15(18.3)^{*}$ & $9.5(12.3)$ & $13(13.3)^{*}$ & $0(0)$ & 0.001 \\
\hline Dexamethasone & $12.5(7)^{*}$ & $4(6)$ & $9.5(10.3)$ & $0(1)$ & 0.01 \\
\hline Sham & $2(4.3)$ & - & - & - & \\
\hline \multicolumn{6}{|l|}{ Septal thickening } \\
\hline Control & $14.5 \pm 10.9$ & $20.0 \pm 6.7$ & $16.8 \pm 10.0$ & $3.2 \pm 2.3$ & NS \\
\hline Dexamethasone & $12.0 \pm 5.5$ & $18.7 \pm 7.8$ & $16.5 \pm 5.5$ & $3.2 \pm 3.7$ & NS \\
\hline Sham & $10.0 \pm 7.5$ & - & - & - & \\
\hline
\end{tabular}

NS: non-significant. aData are expressed as mean \pm SD or median (interquartile range). ${ }^{b}$ Overall significance of the differences among the time points within each group (one-way ANOVA). *p $<0.05$ vs. sham group (Dunnett's test). ${ }^{\dagger} \mathrm{p}<0.05$ vs. control at the same time point. 


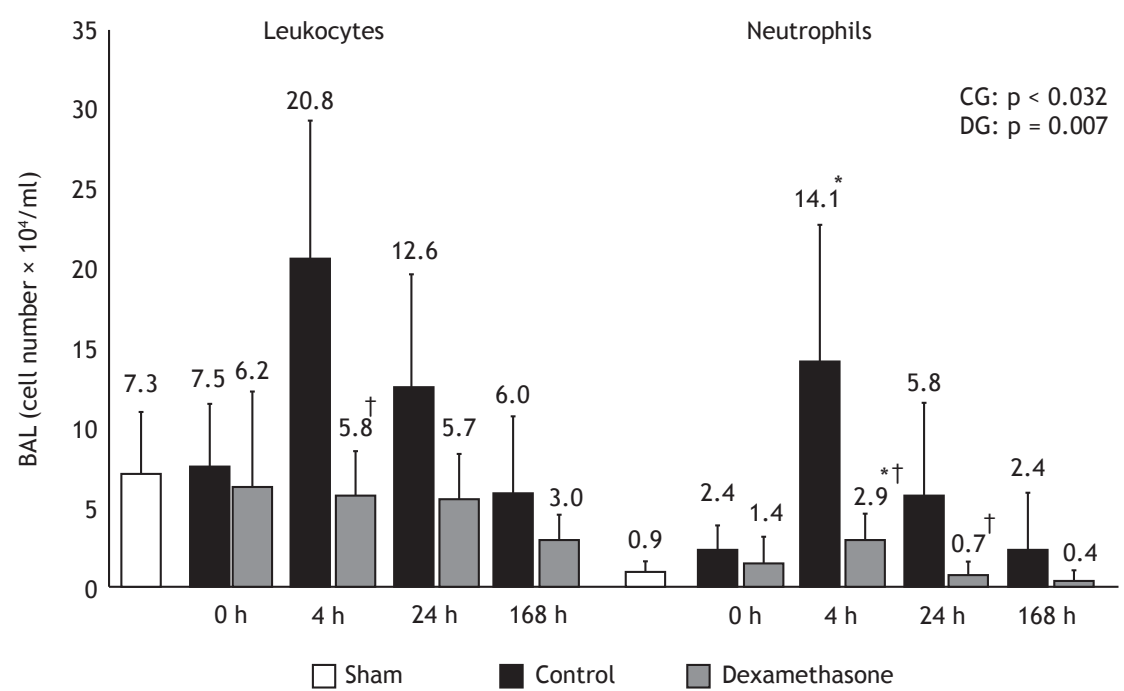

Figure 4. Leukocytes and neutrophils (number of cells $\times 10^{4} / \mathrm{mL}$ ) in the BAL fluid, by group, as well as by time point after the induction of ventilator-induced lung injury in the dexamethasone group (DG) and control group (CG). The $\mathrm{p}$-values indicate the overall significance of the differences among the time points and within each group (one-way ANOVA). ${ }^{*} p<0.05$ vs. sham group. ${ }^{\dagger} p<0.05$ vs. control at the same time point.

Table 2. Arterial blood gases in rats submitted to $10 \mathrm{~min}$ of protective mechanical ventilation (sham group) or $1 \mathrm{~h}$ of injurious mechanical ventilation, as well as lung wet-to-dry weight ratio in the latter (dexamethasone and control) groups, which were evaluated over time. ${ }^{a}$

\begin{tabular}{|c|c|c|c|c|c|}
\hline \multirow{2}{*}{$\begin{array}{c}\text { Variable } \\
\text { Group }\end{array}$} & \multicolumn{4}{|c|}{ Time point } & \multirow[t]{2}{*}{ p } \\
\hline & $\mathbf{O} \mathbf{h}$ & $4 h$ & $24 h$ & $168 \mathrm{~h}$ & \\
\hline \multicolumn{6}{|l|}{$\mathrm{PaO}_{2}(\mathrm{mmHg})$} \\
\hline Control & $222 \pm 98^{*}$ & $274 \pm 87$ & $387 \pm 31$ & $335 \pm 71$ & 0.003 \\
\hline Dexamethasone & $279 \pm 76$ & $313 \pm 131$ & $388 \pm 71$ & $385 \pm 21$ & NS \\
\hline Sham & $388 \pm 26$ & - & - & - & \\
\hline \multicolumn{6}{|l|}{$\mathrm{PaCO}_{2}(\mathrm{mmHg})$} \\
\hline Control & $52 \pm 9$ & $49 \pm 6$ & $54 \pm 6$ & $57 \pm 10$ & NS \\
\hline Dexamethasone & $51 \pm 6$ & $44 \pm 4$ & $52 \pm 10$ & $51 \pm 12$ & NS \\
\hline Sham & $51 \pm 12$ & - & - & - & \\
\hline \multicolumn{6}{|l|}{$\mathrm{pH}$} \\
\hline Control & $7.25 \pm 0.05$ & $7.28 \pm 0.05$ & $7.27 \pm 0.04$ & $7.26 \pm 0.09$ & NS \\
\hline Dexamethasone & $7.26 \pm 0.02$ & $7.26 \pm 0.04$ & $7.27 \pm 0.06$ & $7.27 \pm 0.05$ & NS \\
\hline Sham & $7.30 \pm 0.08$ & - & - & - & \\
\hline \multicolumn{6}{|l|}{$\mathrm{HCO}_{3}(\mathrm{mEq} / \mathrm{L})$} \\
\hline Control & $22.6 \pm 1.3$ & $23.0 \pm 3.3$ & $23.0 \pm 2.0$ & $24.1 \pm 2.7$ & NS \\
\hline Dexamethasone & $21.7 \pm 2.5$ & $19.3 \pm 2.6$ & $22.2 \pm 2.2$ & $24.3 \pm 2.6$ & NS \\
\hline Sham & $21.9 \pm 1.0$ & - & - & - & \\
\hline \multicolumn{6}{|l|}{ Lung W/D weight ratio } \\
\hline Control & $4.9 \pm 0.2$ & $4.8 \pm 0.7$ & $4.5 \pm 0.2$ & $4.5 \pm 0.1$ & NS \\
\hline Dexamethasone & $4.9 \pm 0.3$ & $4.7 \pm 0.4$ & $4.4 \pm 0.1$ & $4.9 \pm 0.5$ & NS \\
\hline
\end{tabular}

NS: non-significant; and W/D: wet-to-dry. ${ }^{a}$ Data are expressed as mean \pm SD. 'OVverall significance of the differences among the time points within each group (one-way ANOVA). ${ }^{*} p<0.05$ vs. sham group (Dunnett's test).

overinflated by the high tidal volumes. ${ }^{(29)}$ Corticosteroids are able to inhibit both pathways, thereby reducing the influx of neutrophils into the lungs as well as their activation, thus inhibiting or minimizing the injury they induce. ${ }^{(25,30)}$ These corticosteroid effects could explain our findings, which showed that the treated animals presented lower numbers of neutrophils in the BAL fluid, as well as less interstitial/alveolar infiltration by neutrophils and, consequently, milder lung injury.

Most experimental studies of the effects of corticosteroids on VILI have been conducted in the acute phase of the injury and have shown that these anti-inflammatory agents are able to decrease the VILI-induced release of local/systemic cytokines, neutrophil infiltration of the lungs, histological alterations, and functional impairment. $(23,25,28,29)$ In the present study, we showed that, in addition to those acute benefits, dexamethasone maintained the inflammation and lung injury at lower levels throughout the period of recovery after VILI induction.

In another experimental model of VILI, Hegeman et al. (22) showed that dexamethasone inhibits neutrophil 
influx and inflammatory mediator expression, as well as preventing vascular endothelial growth factor expression in the lungs. The authors found such expression to be associated with vascular leakage and with regulation of vascular permeability. However, they did not observe a protective effect of dexamethasone against alveolar-capillary barrier dysfunction, finding that glucocorticoid treatment had no effect on protein levels in the BAL fluid or on the lung wet-to-dry weight ratio. ${ }^{(22)}$ The same result in relation to the lung wet-to-dry weight ratio was observed in our study. It has been shown that dexamethasone can increase extravascular lung water in animals exposed to hyperoxia, countering its positive effects on pulmonary injury so that the overall effect is neutral or even deleterious. ${ }^{(31)}$

We observed a lower mortality rate among the animals treated with dexamethasone than among those in the control group, although the difference was not statistically significant. This might have occurred because the number of animals studied was insufficient, given that survival was not an outcome for which we had planned. The study design prevented us from determining the cause of death in the 11 animals that died. Nevertheless, because those deaths occurred within the first hours after VILI induction, a period during which the levels of lung inflammation and injury were highest, we can hypothesize that they were related to the lung injury. We can also infer that dexamethasone had a positive effect on survival. Another possible hypothesis, based on the results of other studies, is that VILI could have generated a systemic inflammatory response, with hemodynamic instability, that might have been improved by the administration of dexamethasone. (32) This hemodynamic effect was demonstrated by Nin et al., ${ }^{(25)}$ who showed, in another experimental model of VILI, that the administration of dexamethasone attenuated the lung injury and avoided the hemodynamic instability seen among the animals that did not receive pre-treatment.
We chose to ventilate rats at a tidal volume of 35 $\mathrm{mL} / \mathrm{kg}$, on the basis of previous studies that have used the same settings to study VILI and the effects of therapeutic strategies. ${ }^{(25,33,34)}$ Although that tidal volume might seem quite distant from what is employed in clinical practice, it should be borne in mind that, in ARDS, the alveolar area available to ventilation is highly limited (the so-called "baby lung" concept), and the tidal volume (which is set according to the ideal body weight) delivered to those available areas can be extremely high. ${ }^{(35)}$

Our study has some limitations that should be considered. The analyses carried out at the different time points were performed only with the surviving animals, which constitutes a bias. The results obtained at each time point within the dexamethasone and control groups were compared with those obtained for the sham group, in which the animals were ventilated for only $10 \mathrm{~min}$ with a protective strategy. A more precise comparison would have included intubation and extubation of the sham group animals, euthanasia being performed at the same time points as in the other groups.

The design of this study, with induction of VILI followed by extubation and observation for a period of time, does not necessarily correlate with clinical practice. However, it furthers understanding of the course of VILI and of how the use of corticosteroids can alter that course. Although we have demonstrated the temporal evolution of VILI and its inflammatory nature, mainly by showing the capacity of dexamethasone to attenuate the injury, we did not evaluate the pathways involved. In conclusion, we have described the course of VILI induced by high tidal volumes and demonstrated that pre-treatment with dexamethasone is able to attenuate this injury in Wistar rats. The molecular mechanisms and the possible clinical role of corticosteroid therapy in VILI remain to be elucidated.

\section{REFERENCES}

1. Dreyfuss D, Saumon G. Ventilator-induced lung injury: lessons from experimental studies. Am J Respir Crit Care Med. 1998;157(1):294323. http://dx.doi.org/10.1164/ajrccm.157.1.9604014

2. Pinhu L, Whitehead T, Evans T, Griffiths M. Ventilator-associated lung injury. Lancet. 2003;361(9354):332-40. http://dx.doi.org/10.1016/ S0140-6736(03)12329-X

3. Ventilation with lower tidal volumes as compared with traditiona tidal volumes for acute lung injury and the acute respiratory distress syndrome. The Acute Respiratory Distress Syndrome Network N Engl J Med. 2000;342(18):1301-8. http://dx.doi.org/10.1056/ NEJM200005043421801

4. Amato MB, Barbas CS, Medeiros DM, Magaldi RB, Schettino GP, Lorenzi-Filho GP, et al. Effect of a protective-ventilation strategy on mortality in the acute respiratory distress syndrome. N Engl J Med. 1998;338(6):347-54. http://dx.doi.org/10.1056/ NEJM199802053380602

5. Serpa Neto A, Simonis FD, Schultz MJ. How to ventilate patients without acute respiratory distress syndrome? Cur Opin Crit Care. 2015;21(1):65-73. http://dx.doi.org/10.1097/ MCC. 0000000000000165

6. Mechanical Ventilation Committee of the Brazilian Intensive Care Medicine Association; Commission of Intensive Therapy of the Brazilian Thoracic Society. Brazilian recommendations of mechanical

ventilation 2013. Part I. J Bras Pneumol. 2014;40(4):327-63. http:// dx.doi.org/10.1590/S1806-37132014000400002

7. Gattinoni L, Protti A, Caironi P, Carlesso E. Ventilator-induced lung injury: the anatomical and physiological framework. Crit Care Med. 2010;38(10 Suppl):S539-48. http://dx.doi.org/10.1097/ CCM.0b013e3181f1fcf7

8. Slutsky AS, Ranieri VM. Ventilator-induced lung injury. N Engl J Med 2013;369(22):2126-36. http://dx.doi.org/10.1056/NEJMra1208707

9. Tremblay LN, Slutsky AS. Ventilator-induced injury: from barotrauma to biotrauma. Proc Assoc Am Physicians. 1998;110(6):482-8.

10. De Prost N, Dreyfuss D. How to prevent ventilator-induced lung injury? Minerva Anestesiol. 2012;78(9):1054-66

11. Uhlig S, Uhlig U. Pharmacological interventions in ventilator-induced lung injury. Trends Pharmacol Sci. 2004;25(11):592-600. http://dx.doi. org/10.1016/j.tips.2004.09.002

12. Barnes PJ. Corticosteroid effects on cell signalling. Eur Respir J. 2006;27(2):413-26. http://dx.doi.org/10.1183/09031936.06.0012540 4

13. Rhen T, Cidlowski JA. Antiinflammatory action of glucocorticoidsnew mechanisms for old drugs. N Engl J Med. 2005;353(16):1711 23. http://dx.doi.org/10.1056/NEJMra050541

14. Sessler CN, Gay PC. Are corticosteroids useful in late-stage acute 
respiratory distress syndrome? Respir Care. 2010;55(1):43-55.

15. Thompson BT. Glucocorticoids and acute lung injury. Crit Care Med. 2003;31(4 Suppl):S253-7. http://dx.doi.org/10.1097/01 CCM.0000057900.19201.55

16. Agarwal R, Nath A, Aggarwal AN, Gupta D. Do glucocorticoids decrease mortality in acute respiratory distress syndrome? A metaanalysis. Respirology. 2007;12(4):585-90. http://dx.doi.org/10.1111/ j.1440-1843.2007.01060.x

17. Lamontagne F, Briel M, Guyatt GH, Cook DJ, Bhatnagar N, Meade M. Corticosteroid therapy for acute lung injury, acute respiratory distress syndrome, and severe pneumonia: a meta-analysis of randomized controlled trials. J Crit Care. 2010;25(3):420-35. http:// dx.doi.org/10.1016/j.jcrc.2009.08.009

18. Meduri GU, Marik PE, Chrousos GP, Pastores SM, Arlt W, Beishuizen A, et al. Steroid treatment in ARDS: a critical appraisal of the ARDS network trial and the recent literature. Intensive Care Med. 2008;34(1):61-9. http://dx.doi.org/10.1007/s00134-007-0933-3

19. Tang BM, Craig JC, Eslick GD, Seppelt I, McLean AS. Use of corticosteroids in acute lung injury and acute respiratory distress syndrome: a systematic review and meta-analysis. Crit Care Med. 2009;37(5):1594-603. http://dx.doi.org/10.1097/ CCM.0b013e31819fb507

20. Peter JV, John P, Graham PL, Moran JL, George IA, Bersten A. Corticosteroids in the prevention and treatment of acute respiratory distress syndrome (ARDS) in adults: meta-analysis. BMJ. 2008;336(7651):1006-9. http://dx.doi.org/10.1136/ bmj.39537.939039.BE

21. Steinberg KP, Hudson LD, Goodman RB, Hough CL, Lanken PN, Hyzy $R$, et al. Efficacy and safety of corticosteroids for persistent acute respiratory distress syndrome. N Engl J Med. 2006;354(16):1671-84. http://dx.doi.org/10.1056/NEJMoa051693

22. Hegeman MA, Hennus MP, Cobelens PM, Kavelaars A, Jansen NJ, Schultz MJ, et al. Dexamethasone attenuates VEGF expression and inflammation but not barrier dysfunction in a murine model of ventilator-induced lung injury. PLoS One. 2013;8(2):e57374. http:// dx.doi.org/10.1371/journal.pone.0057374

23. Nin N, Lorente JA, de Paula M, El Assar M, Vallejo S, Peñuelas O, et al. Rats surviving injurious mechanical ventilation show reversible pulmonary, vascular and inflammatory changes. Intensive Care Med. 2008;34(5):948-56. http://dx.doi.org/10.1007/s00134-007-0959-6

24. Nin N, Lorente JA, Fernández-Segoviano P, De Paula M, Ferruelo A, Esteban A. High-tidal volume ventilation aggravates sepsisinduced multiorgan dysfunction in a dexamethasone-inhibitable manner. Shock. 2009;31(4):429-34. http://dx.doi.org/10.1097/ SHK.0b013e318188b720

25. Nin N, Peñuelas O, de Paula M, Lorente JA, Fernández-Segoviano
P, Esteban A. Ventilation-induced lung injury in rats is associated with organ injury and systemic inflammation that is attenuated by dexamethasone. Crit Care Med. 2006;34(4):1093-8. http://dx.doi. org/10.1097/01.CCM.0000205663.92384.E7

26. Matute-Bello G, Downey G, Moore BB, Groshong SD, Matthay MA, Slutsky AS, et al. An official American Thoracic Society workshop report: features and measurements of experimental acute lung injury in animals. Am J Respir Cell Mol Biol. 2011;44(5):725-38. http:// dx.doi.org/10.1165/rcmb.2009-0210ST

27. Peterson BT, Brooks JA, Zack AG. Use of microwave oven fo determination of postmortem water volume of lungs. J Appl Physio Respir Environ Exerc Physiol. 1982;52(6):1661-3.

28. Curley GF, Contreras M, Higgins B, O'Kane C, McAuley DF, O'Toole D, et al. Evolution of the inflammatory and fibroproliferative responses during resolution and repair after ventilator-induced lung injury in the rat. Anesthesiology. 2011;115(5):1022-32. http://dx.doi. org/10.1097/ALN.0b013e31823422c9

29. Ohta N, Shimaoka M, Imanaka H, Nishimura M, Taenaka N, Kiyono $\mathrm{H}$, et al. Glucocorticoid suppresses neutrophil activation in ventilatorinduced lung injury. Crit Care Med. 2001;29(5):1012-6. http://dx.doi. org/10.1097/00003246-200105000-00027

30. Held HD, Boettcher S, Hamann L, Uhlig S. Ventilation-induced chemokine and cytokine release is associated with activation of nuclear factor-kappaB and is blocked by steroids. Am J Respir Crit Care Med. 2001;163(3 Pt 1):711-6. http://dx.doi.org/10.1164/ ajrccm.163.3.2003001

31. Ramsay PL, Smith CV, Geske RS, Montgomery CA, Welty SE. Dexamethasone enhancement of hyperoxic lung inflammation in rats independent of adhesion molecule expression. Biochem Pharmacol. 1998;56(2):259-68. http://dx.doi.org/10.1016/S0006-2952(98)001385

32. Imai $Y$, Parodo J, Kajikawa O, de Perrot M, Fischer S, Edwards V, et al. Injurious mechanical ventilation and end-organ epithelial cell apoptosis and organ dysfunction in an experimental model of acute respiratory distress syndrome. JAMA. 2003;289(16):2104-12. http:// dx.doi.org/10.1001/jama.289.16.2104

33. Dreyfuss D, Basset G, Soler P, Saumon G. Intermittent positivepressure hyperventilation with high inflation pressures produces pulmonary microvascular injury in rats. Am Rev Respir Dis. $1985 ; 132(4): 880-4$

34. Eyal FG, Hamm CR, Parker JC. Reduction in alveolar macrophages attenuates acute ventilator induced lung injury in rats. Intensive Care Med. 2007;33(7):1212-8. http://dx.doi.org/10.1007/s00134-0070651-x

35. Gattinoni L, Pesenti A. The concept of "baby lung". Intensive Care Med. 2005;31(6):776-84. http://dx.doi.org/10.1007/s00134-0052627-z 